\title{
Alumni/ae Surveys as Tools for Directing Change in Engineering Curriculum
}

\author{
Chris K Mechefske, Urs P Wyss, Brian W Surgenor and Natalie Kubrick \\ Department of Mechanical and Materials Engineering \\ Queen's University, Kingston, Ontario, K7L 3N6 \\ chrism@me.queensu.ca
}

\begin{abstract}
Like any other similar department, the Department of Mechanical and Materials Engineering (MME) at Queen's University adapts the undergraduate curriculum on an ongoing basis using input from students, faculty, alumni/ae and other sources. Of particular usefulness have been alumni/ae survey results. These results have allowed priorities for curriculum changes to be set with the confidence that graduates will be well equipped to meet the demands of a changing workplace. This paper describes the results of the most recent survey. Many of the suggested changes to the curriculum have already been implemented. One of the ongoing challenges of the Department will be to repeat the survey regularly in the future, to see if the current changes made a difference in terms of employer and graduate satisfaction.
\end{abstract}

\section{Introduction}

The expectations industry and other employers have of our graduates are changing with time, partially due to changes in society, but also due to changes in how industry adapts to new developments in technology. In particular, communication, teamwork and the enormous advances in information technology have changed what is expected from graduates, along with the fact that a solid knowledge in the core technical subjects is still required.

There are several ways to get feedback about what needs to change (if anything) in an undergraduate curriculum. One important method for Queen's MME has been the establishment of an Advisory Council (AC). This is a group of 3-5 former students who have been working in industry for several years. They visit the Department once per year, talk with students, staff and faculty, and write a report about the issues that need to be addressed, and how well previous recommendations have been implemented. In the past the $\mathrm{AC}$ visits were a requirement in the Faculty of Applied Science at Queen's. Currently these visits are no longer mandatory, but are still considered to be extremely important and the MME department has decided to continue these annual assessments. There is also an anonymous University Survey of Student Assessment and Teaching (USAT) conducted near the end of each teaching term that provides feedback to individual instructors and the Head of the Department.

Engineering education meetings and journals, as well as talking to colleagues at conferences, is another source for input about possible improvements in the program. The MME department At Queen's felt that the Conceive Design Implement Operate (CDIO) initiative could be a tool well suited to review the curriculum in a more organized way. The work previously done by the other CDIO collaborators on curriculum, teaching and learning, assessment and workspace convinced the faculty in the Department of Mechanical and Materials Engineering to join the initiative in December 2003.

In the summer of 2004 a survey about the engineering curriculum was conducted. Alumni/ae from the 2004 to the 1970 graduating classes were contacted. The goals of the survey were to ensure that students are taught what is required of graduating engineers today. The results from the survey have already been used in preparation of documentation required by the Canadian Engineering Accreditation Board (CEAB) for a 6 year extension of the MME program. The results of the survey will also be a benchmark for future surveys, and for benchmarking with other programs in Canada and abroad. The survey was based on the CDIO version looking at "personal and professional skills and attributes" and "operating systems in the enterprise and societal context", or the so called soft skills. 
The question about communications in a foreign language was omitted as there is no such requirement from the CEAB. The survey also included questions about mathematics, engineering sciences and additional core subjects, similar to an earlier survey done at Queen's University at Belfast. The survey was tested and modified with the help of a small number of faculty, graduate and undergraduate students, before it was mailed to the alumni/ae. Based on this initial feedback, it was concluded that the responses to questions should be simplified as illustrated in Figure 1.

\section{Results of the Survey}

Over 3,000 surveys were sent out. More than 400 responses, or almost $15 \%$ percent, were returned and analyzed. Of the ones returned $10.6 \%$ were from female and $89.4 \%$ were male respondents. The respondents could also be divided into one group that graduated after $1994(37.2 \%)$ and a group that graduated between 1970 and 1993 (62.8\%). There were $38 \%$ who were still mainly employed in an engineering related position, $43 \%$ had moved on to mainly management activities, $2 \%$ had retired and the remaining $17 \%$ were in other positions, such as finance, sales and teaching.

The results of the section "personal and professional skills and attributes" of the CDIO survey are shown for the more recent graduates and those who graduated before 1994 in Figure 2. The results from the "operating systems in the enterprise and societal context" questions are shown in Figure 3. The data was also analyzed for male/female differences but no significant differences were found.
In addition to the so-called "soft skills" from the CDIO survey, some aspects of the core curriculum were part of the survey and were also analyzed. The answers in the areas of thermodynamics, fluid mechanics, engineering dynamics and kinematics indicate that teaching the principles and how to apply them is clearly more important than deriving these same principles. The results about the knowledge in the different areas of mathematics are shown in Figure 4.

Additional feedback was generated regarding the importance of other courses taught in the MME program. Project management was the course with the highest rating (4.1. The lowest ranking was 2.8 for marketing methods and practices, with the other 17 subjects in-between.

There was space provided for additional comments and about a third of the over 400 respondents added comments. These comments were grouped into the four following categories:

- More practical applications $\quad 38 \%$ (real world issues)

- Excellent communication skills $21 \%$

- $\quad$ More group projects - teamwork $\quad 27 \%$

- Other

$14 \%$

Circle one of the level of importance that you believe a newly BSc graduate engineer should have

\begin{tabular}{|ll|}
\hline & $\begin{array}{ll}\text { 1. Considerably less important than the others } \\
\text { Please answer topics } & \text { 2. Less important than the others } \\
\text { on the basis of your } & \text { 3. Of average importance } \\
\text { own personal experience } & \text { 4. More important than the others } \\
& \text { 5. Considerably more important than the others }\end{array}$
\end{tabular}

Figure 1: Potential survey answer selections. 


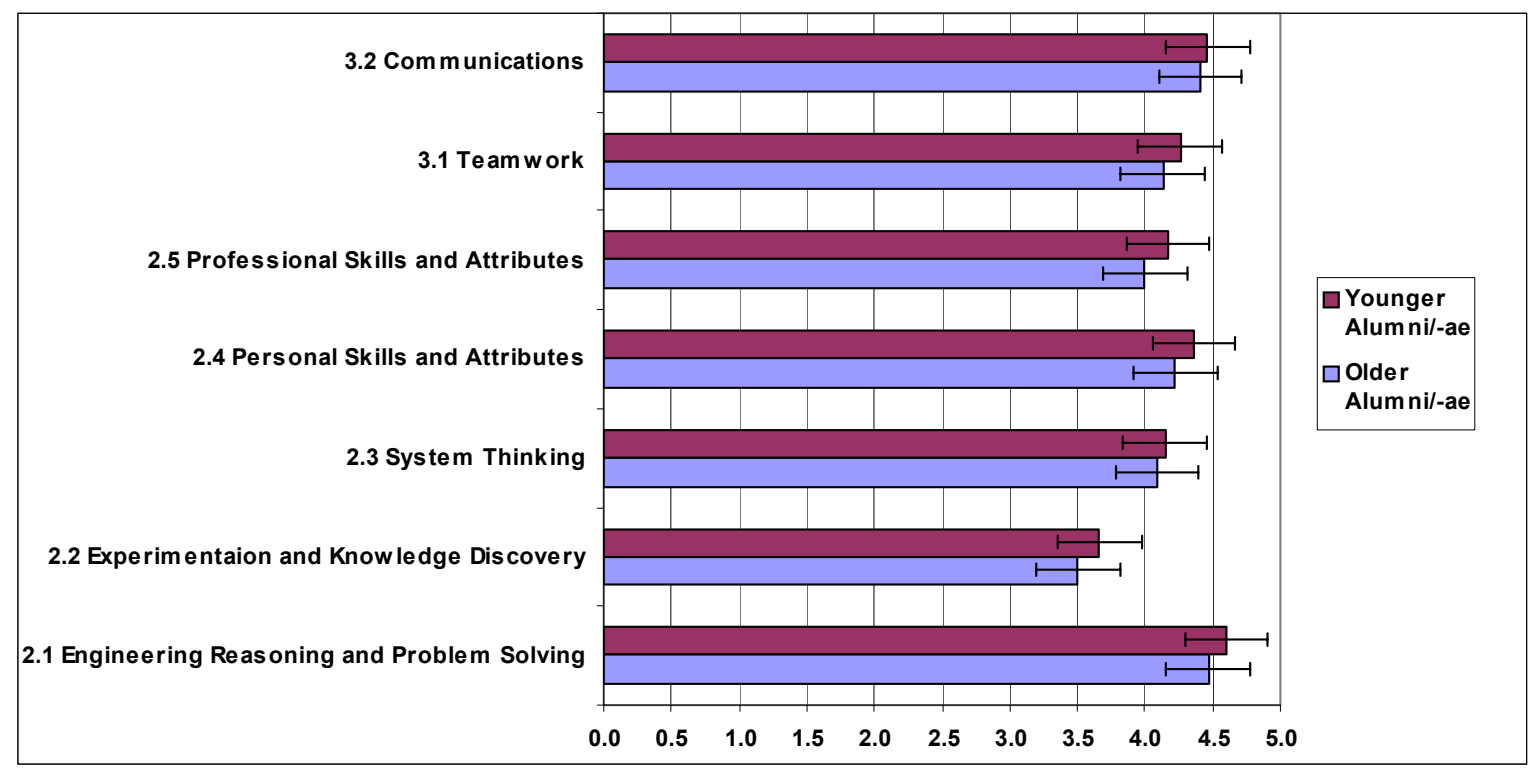

Figure 2: Personal and professional skills and attributes (+/- 1 S.D.).

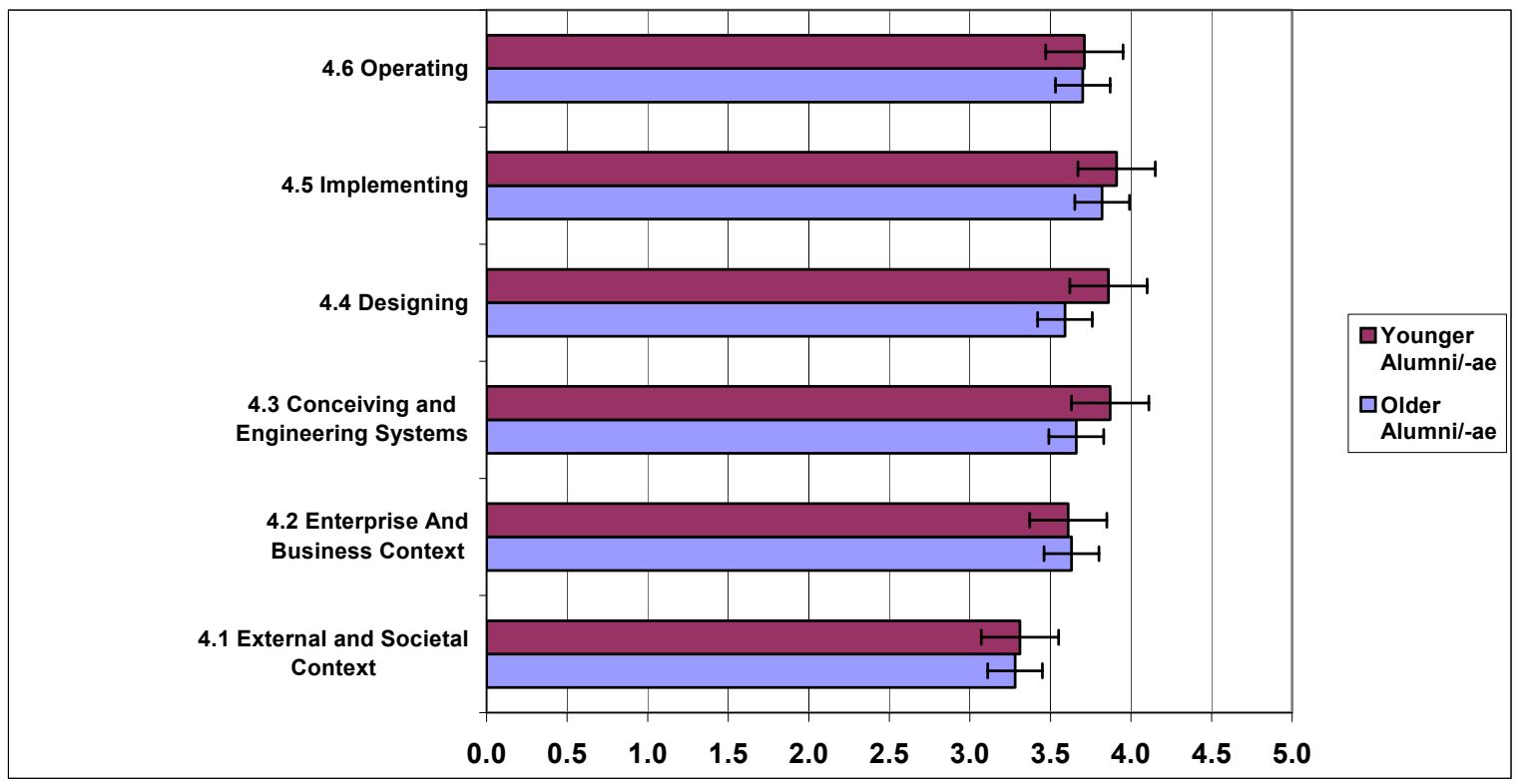

Figure 3: Operating systems in the enterprise and societal context (+/- 1 S.D.). 


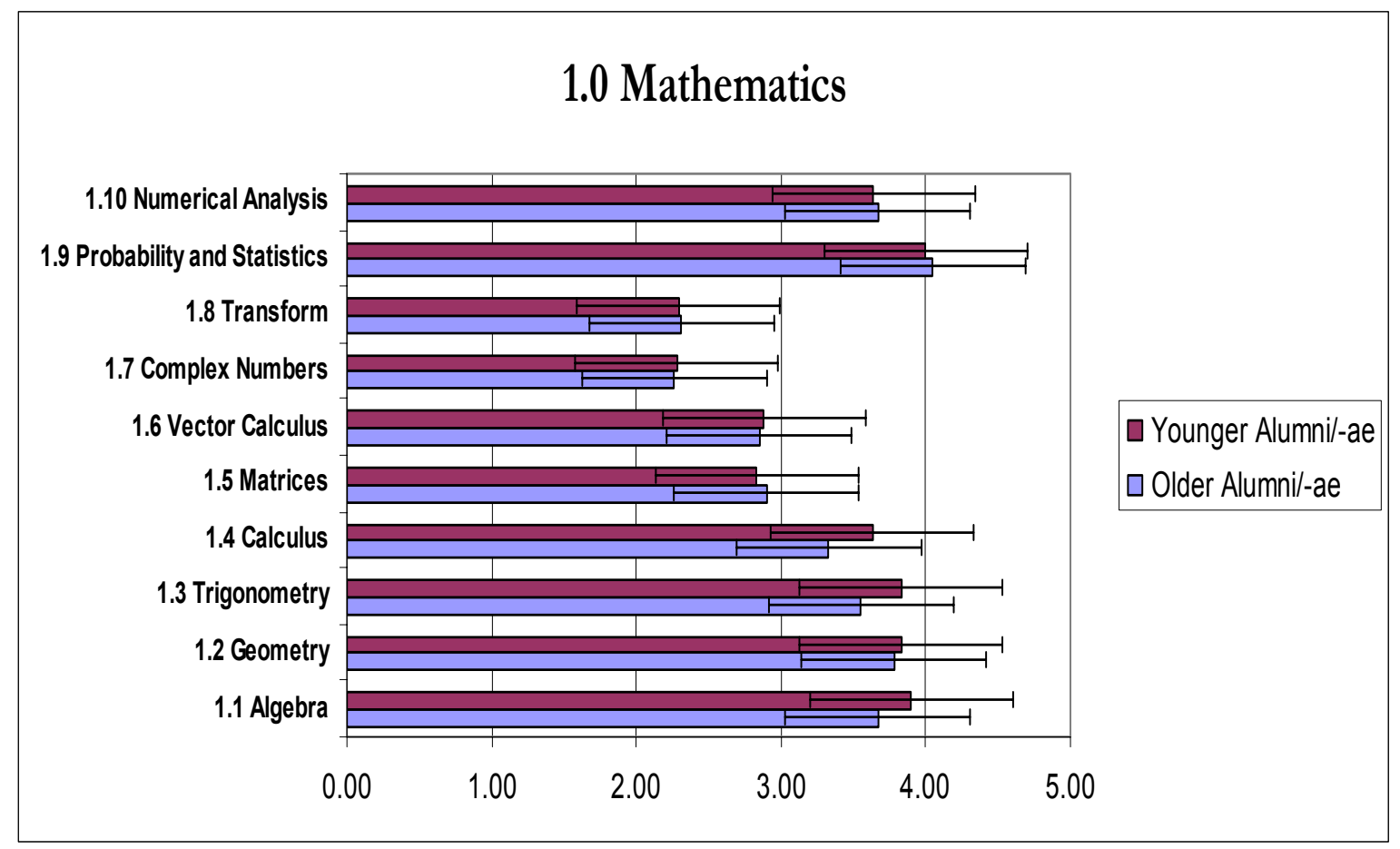

Figure 4: The importance of the different subjects in mathematics (+/- 1S.D.).

\section{Discussion}

Almost $15 \%$ of the surveys mailed were returned, providing an excellent basis for reviewing the curriculum with over 400 "opinions" from our own graduates between 1970 and 2004. The experience of other groups with this type of survey suggested that there were some problems interpreting the questions. The simplified form of answer (see Figure 1) adopted in the survey largely eliminated problems answering the questions.

All the personal and professional attributes and interpersonal skills (Figure 2) seem to be important with ratings of 3.5-4.5 out of 5. The lowest rating was given to experimentation and knowledge discovery (2.2). The attributes in operating systems in the enterprise and societal context (Figure 3) were between 3.3 and 3.8, with the lowest being external and societal context (4.1).

It is interesting to note that in Figure 4, probability and statistics was rated high by alumni/ae with a score of four, while transforms and complex numbers were not rated highly with scores around 2.3. The largest deficit in the core program was found to be in
Enterprise and Business Context (4.2), Implementing (4.5) and Operating (4.6).

The MME core program was also benchmarked with the CDIO syllabus as outlined by Bankel [1]. There is no fixed set of technical electives for the areas of specialization in manufacturing and design, biomechanical, mechatronics, aerospace engineering, and thermodynamics and fluids in the MME program at Queen's. Only the materials option within MME has a defined set of courses for specialization. This limits the number of technical electives a student can choose within this option.

The scale used at Queen's is not exactly the same as the one used by the Swedish universities Chalmers, KTH and Linkoeping or the MIT in earlier surveys. This means a detailed comparison is difficult.

The results of the survey have led to a few changes in the curriculum of the MME department at Queen's. In particular the oral and written communication course has been changed to have about half of the material linked to communication requirements in 
other courses. Furthermore, communication will be taught in first, second and third year of the four year program, so that it will be an on-going process. The initial feedback by students and faculty is very positive. A second major change resulted in increased efforts to have industry-sponsored projects in our fourth year capstone course, and also as much as possible in other design-related undergraduate courses.

\section{Conclusions}

The CDIO based survey is a very useful tool when reviewing the curriculum. It provides hard data from engineers who have graduated from a particular program In the case of the MME program at Queen's University over 400 respondents provided valuable feedback. The survey results help to focus discussion on the issues that matter, rather than getting lost in less important details. It also helps to neutralize strong opinions based on research preferences held by some individual faculty members.

The mechanical and materials engineering program at Queen's has already adopted a new methodology of when and how oral and written communication teaching will be provided. Furthermore, the conceive and deign $(\mathrm{CD})$ components of the $4^{\text {th }}$ year design capstone course and the implement and operate (IO) components in $4^{\text {th }}$ year have also been strengthened.

Additional changes in the curriculum will be necessary to further decrease the gap between what industry needs and what is being taught. An additional challenge will be to convince more faculty members to introduce aspects of the CDIO syllabus in their courses. Benchmarking entering and exiting students, as well as follow-up alumni/ae surveys will indicate if the curriculum changes provide a program closer to what is required by industry and other employers.

\section{References}

[1] Bankel, J., "Benchmarking Engineering Curricula with the CDIO Syllabus", International Journal of Engineering Educaiton, 2005, Vol. 21, pp.121-133. 